\title{
Welcome Neurology International Open
}

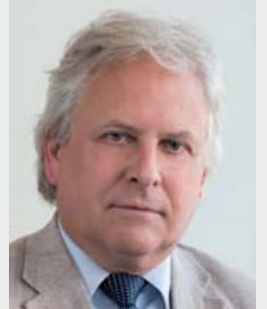

Prof. Hans-Christoph Diener

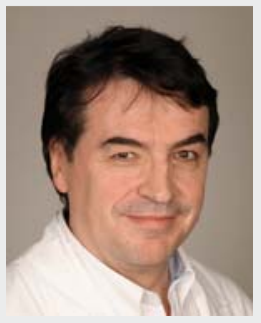

Dr. Günter Krämer
We are delighted to introduce you the very first issue of "Neurology International Open" (NIO). This new journal starts as an open access companion to German journal "Aktuelle Neurologie" (Current Neurology) ensuring faster access to the most relevant and up-to-date developments in neurology and neuroscience for an international readership.

$\mathrm{NIO}$ is an open access journal complying with the same strict scientific standards as Aktuelle Neurologie. Thieme publishers is committed to excellent editorial work on manuscripts and fast peer-review. The journal will contain original pages, review articles, guidelines of the German Society of Neurology, editorials and letters to the editors. We invite and encourage submissions from all regions of the world, as tremendous ideas and research work are being generated from all over. "Open Access" means that every person with an internet connection can access, read and download these articles.

Thieme publishers and the editors are looking forward to developing this journal for the international neurology community as a truly innovative platform for the exchange of clinical research in neurology. Authors who are interested in publishing in NIO will find all the necessary information on www.thieme.de/nio and https:// mc.manuscriptcentral.com/nio.

We look forward to receiving your submissions which will contribute to the success of the journal!

We hope you enjoy your reading!

Prof. Dr. Hans-Christoph Diener Dr. Günter Krämer

Editors Neurology International Open 